\title{
Combining seed burial, land imprinting and an artificial soil crust dramatically increases the emergence of broadcast seed
}

MP Dobrowolski Iluka Resources Limited, and The University of Western Australia, Australia

\begin{abstract}
Seedling emergence from broadcast seed is notoriously low in mining rehabilitation. At Iluka Resources' Eneabba mine in the Mid West of Western Australia, eight-fold more seedlings emerged under ideal nursery conditions in 2015 than when that seed was broadcast in the field. Unlocking this potential in broadcast seed is critical to establish the desired plant density and species diversity of restored kwongan shrubland vegetation.

Erosion, both wind and water, is a major factor affecting seedling emergence in newly rehabilitated mines sites. To control wind erosion at Eneabba, lluka applies a crust of dilute, non-toxic bitumen emulsion to the sandy soil surface. This crust degrades over a few years but does not inhibit germination. It allows seedlings to emerge and establish under windy conditions, common at Eneabba, holding the seed in the soil matrix for germination to occur and eliminating the sand-blasting that kills newly emerged seedlings. Combining this crust application with ripping-mounding to prevent water erosion in 2016 increased seedling establishment almost two-fold.

Land imprinting, a technique developed in the 1970s, reduces rainfall runoff and increases infiltration and nutrient/organic matter accumulation thereby improving seedling emergence and establishment. However, the imprints erode too quickly in sandy soils like those at Eneabba. A trial in 2017, combining land imprinting and bitumen emulsion crust increased seedling emergence more than two-fold for broadcast seed and threefold for topsoil-derived seed.

Burial of the diverse sized and shaped seed, for improved germination, was achieved in 2018. This combined with land imprinting and crust application increased seedling emergence from broadcast seed by $50 \%$ on the 2017 trial.

Data from large-scale field trials of these rehabilitation practices and their innovative combination will be presented to illustrate their effectiveness and applicability in other projects. New, custom-built seeding, land imprinting and crust application equipment used in 2019 Eneabba rehabilitation will be unveiled.
\end{abstract}

Keywords: revegetation, land imprinting, mining rehabilitation, seed

\section{Introduction}

Broadcast seeding is a primary method of re-establishing plant species into rehabilitated mines. When reestablishing a diverse native vegetation, this seed can take a variety of size, shape and form that is difficult to broadcast and difficult to control its placement to achieve optimal seed germination and seedling emergence. Even for crop species, the key abiotic and biotic factors affecting germination and emergence are not well quantified (Lamichhane et al. 2018). For the diverse range of native plant species like those at found Eneabba, these factors are largely unknown and unlikely to be investigated in detail given the cost and time required. Therefore, a pragmatic approach is necessary to improve germination and emergence, identifying and trialling practices to ameliorate the limiting factors in the environment found in mining rehabilitation.

At Eneabba the key factors limiting germination and emergence in mining rehabilitation are likely to be abiotic and related to the climate and soils of the region. Iluka Resources' Eneabba mine is located in the Mid West of Western Australia, approximately $250 \mathrm{~km}$ north of Perth and $30 \mathrm{~km}$ from the coast (Figure 1). 
The climate of Eneabba is Mediterranean with annual rainfall nearly $500 \mathrm{~mm}$, mostly falling in winter, with a pronounced summer drought typically lasting five to six months (Figure 1). Summer maximum temperatures average over $36^{\circ} \mathrm{C}$. Summer is also the windiest period with winds commonly exceeding $30 \mathrm{~km} / \mathrm{h}$, easterly during the night and morning, southwesterly in the afternoon, and occasionally exceeding 40 or $50 \mathrm{~km} / \mathrm{h}$. The soils of the region are typically sandy with poor water retention capacity. Hence, wind erosion of freshly placed topsoil can be severe with these windy conditions readily removing sown seed. Seedlings can also be killed by sand-blasting with mobile sand in their first summer. The climate also provides only a short seasonal window for seedlings to establish and grow roots deep enough to survive the pronounced summer drought.
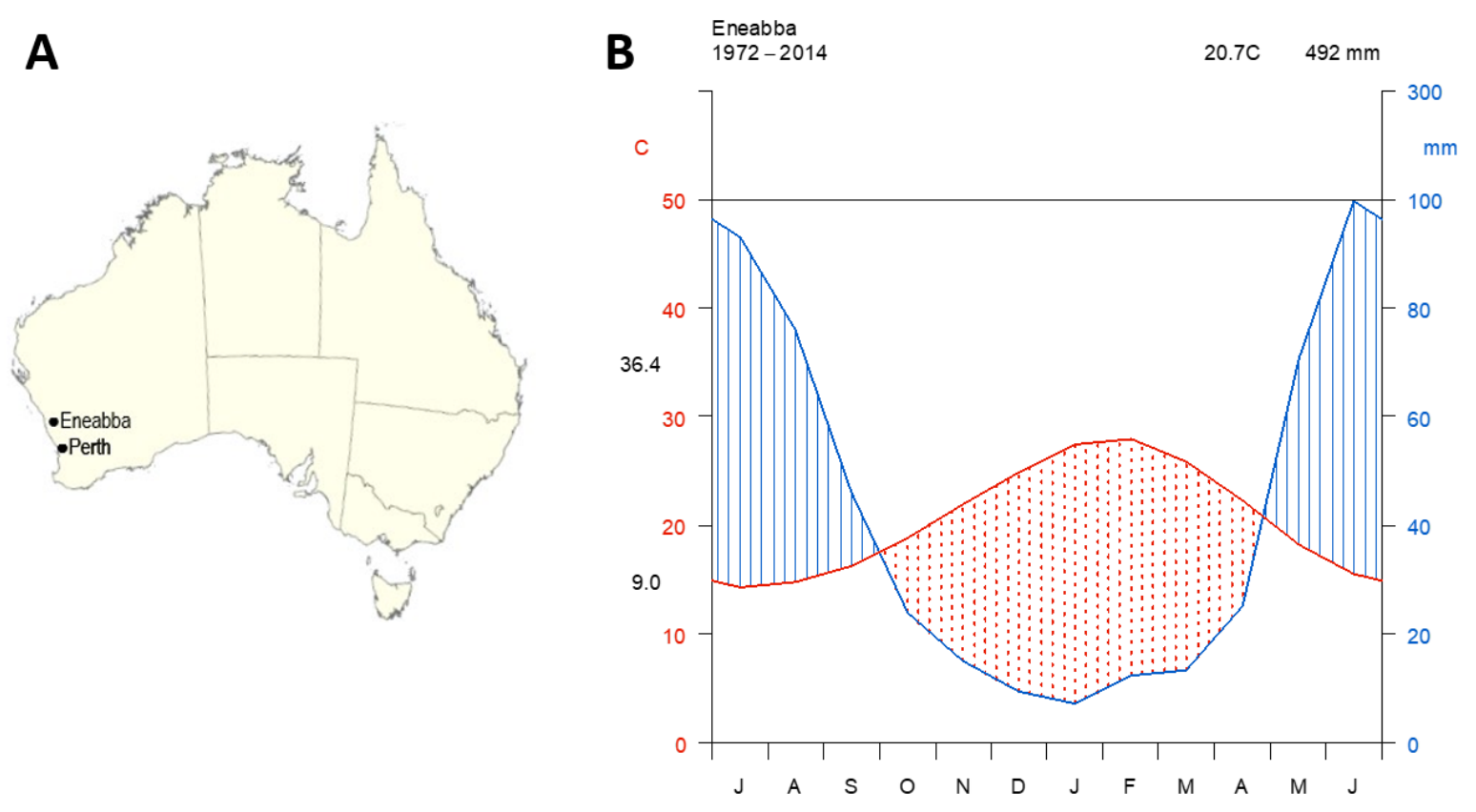

Figure 1 (a) Location of Iluka's Eneabba mine in the Mid West of Western Australia; and (b) Walter-Leith diagram of the monthly rainfall and daily average temperature of Eneabba

The native vegetation predominant at Eneabba is known as kwongan, a low, sclerophyllous scrub occurring on nutrient-poor sandy soils in Western Australia, known for its exceptionally high species richness and an absence of dominant species (Tsakalos et al. 2018). lluka aims to restore a diverse and functional kwongan vegetation in its rehabilitated mine areas at Eneabba that is resilient to natural disturbance such as bushfire. When the mineral sands mine was operational, topsoiled rehabilitation areas were spread with mulch collected from the mine path or adjacent natural vegetation. This native mulch was of enormous benefit for rehabilitation by providing $89 \%$ of the germinable seed in rehabilitation (mostly from bradysporous species) and niches for emerging seedlings (Bellairs \& Bell 1993), and by stabilising the soil surface against wind erosion (Bell et al. 1986). With mining now idle at Eneabba, native mulch is no longer accessible. Topsoil is another important source of seed, however available topsoil resources are poor quality. Topsoil stockpiles are over 10 years old and most were derived from areas previously rehabilitated, therefore having a low content and a limited diversity of germinable seed. Broadcast seed that is hand-picked, therefore, has become the primary method to re-establish the diversity of plant species required in the rehabilitated mine areas. Given this seed is sourced from surrounding remnant vegetation, lluka wishes to minimise its impact on the remnant vegetation by maximising the germination and emergence of broadcast seed. This will allow lluka to increase the area of land rehabilitated while still restoring a diverse and functional kwongan vegetation.

Without native mulch, alternatives were required to control wind erosion of freshly placed topsoil in rehabilitated areas at Eneabba. Nurse crops such as cereal rye (Secale cereale) were used at Eneabba for a few years. However, the known allelopathic effect of root exudates from cereal rye on germinating seed (Barnes \& Putnam 1986) and the allelopathy of wild and cultivated Poaceae species more generally (SánchezMoreiras et al. 2003) motivated investigation of alternative soil stabilising methods. There are a number of 
artificial soil crust agents that are commercially available, such as those based on polyvinyl acetate glue. A less expensive crust agent is dilute bitumen emulsion (also known commercially as Terolas ${ }^{\circledR}$ ), which has been successfully used since the 1970 s to control wind erosion in native vegetation rehabilitation at a mineral sands mine on North Stradbroke Island, Queensland (van der Westhuizen et al. 2011).

Land imprinting is another rehabilitation method used to improve germination of broadcast seed. Developed in the arid rangelands of the western United States, land imprinting aims to increase rainfall infiltration and nutrient capture/recycling in situ by physically indenting the soil surface with a ridged roller to create microcatchments that harvest about five litres of water each (Dixon 1995). It is based on the channel system concept whereby improved infiltration is achieved under a pressure head in the micro-catchments, with the dry ridges allowing soil air pressure to be released (Dixon \& Peterson 1971). The concept is reminiscent of the patch/interpatch processes or the trigger-transfer-reserve-pulse framework (Tongway \& Ludwig 1997), which is the basis of landscape function analysis. Imprinting could be considered an artificial way to improve these processes. Improved establishment of vegetation from seed has been demonstrated with land imprinting (Montalvo et al. 2002) but in sandy soils the indentations do not persist long enough because of wind and water erosion (Bainbridge 1996). At least in a finer textured soil, land imprinting also reduced runoff and resulting water erosion by an order of magnitude (Granada-Isaza et al. 2012).

In the sandy soils of Eneabba, the combination of soil imprinting stabilised with a dilute bitumen emulsion crust could increase soil moisture through improved rainfall infiltration, and reduce wind and water erosion losses of broadcast seed and seedlings, thus improving seedling establishment. This paper presents data from large-scale field trials, and data from more general monitoring of rehabilitation conducted over successive years at lluka's Eneabba mineral sands mine, evaluating the performance of the above practices on the germination and emergence of native vegetation from broadcast seed.

\section{Methods}

The trials and implementation of the different rehabilitation practices occurred from 2015 to 2019 within different areas each year at lluka's Eneabba mine in native vegetation rehabilitation. In all years, standard lluka practice was to re-contour the mine pits and tailings dams to blend with the surrounding topography and reduce all slopes to less than 1 in 10. Mineral sands tailings is produced from a wet separation process and can be coarse sand tailings or fine-textured, clayey material or a mixture of the two. Overburden or subsoil, when available, was also used in re-contouring. Soil profiles were therefore highly variable across the rehabilitation areas. Upon this surface $100-200 \mathrm{~mm}$ of topsoil was spread using tractor pulled carry-graders. Topsoil was of poor quality, sandy textured with little or no clay-sized particles, and stockpiled for 10 or more years. It was also taken from areas previously rehabilitated, hence contained few germinable seed apart from hard seedcoat species such as Acacia blakelyi and Acacia pulchella. The different rehabilitation practices trialled are described in the experimental description and results section.

The seed mix broadcast each year consisted mostly (approximately 80\%) of species from Proteaceae, Myrtaceae, Fabaceae and Ericaeae plant families but many other families were included as well. Individual species may have differed year-to-year depending on seasonal availability in remnant vegetation but total species numbers ranged from 100 in 2015 to 160 in 2019 (116 in 2016, 153 in 2017, 159 in 2018). Application rates of seed were $3 \mathrm{~kg} / \mathrm{ha}$ in 2015 and $4.5 \mathrm{~kg} / \mathrm{ha}$ in subsequent years.

Assessment of broadcast seed emergence used randomly placed $4 \mathrm{~m}^{2}$ quadrats in 2015, and from 2016 onwards used randomly placed $4 \mathrm{~m}$ wide variable area transects (VATs), given VATs' superiority (accuracy and efficiency) in estimating plant density (Engeman et al. 2005). Monitoring was done in late spring (November) following seeding of the rehabilitation area in the autumn (April/May). Seedlings were identified to genus or family level (species level identification is impossible at the seedling stage for many species in kwongan, even for expert botanists) and in VATs seven individuals of each plant group were counted before recording the transect length, the plant groups being: Myrtaceae; Proteaceae; topsoil-derived species (A. blakelyi and A. pulchella); other native perennial species; native annuals, and; weeds (all annuals). 
Robust statistics were used for estimation: all means were $20 \%$ trimmed means and all $95 \%$ confidence intervals used the percentile bootstrap method (Wilcox 2012) using R (R Core Team 2013).

\section{Experimental description and results}

\subsection{5 soil stabilisation trial}

The 30 ha of native vegetation rehabilitated in 2015 was designed as a large-scale trial with the area divided into 11 plots testing various combinations of soil stabilisation. Those treatments included a nurse crop of cereal rye, application of dilute bitumen emulsion (approximately 20,000 L/ha of 1 in 11 dilution of anionic slow set $60 \%$ (ASS-60) bitumen emulsion), a combination of cereal rye and bitumen emulsion, and control (no soil stabilisation treatment). Ripping of the soil profile prior to seeding is standard practice at lluka to relieve compaction allowing roots to penetrate deep into the profile. Ripping was carried out in 2015 using a D10 dozer using a winged tine along the contour to $0.8 \mathrm{~m}$ deep to reduce water erosion and increase infiltration. Native seed was broadcast by hand. The order of implementation of these practices was: seeding with cereal rye (by agricultural equipment in designated plots); ripping; native seed broadcast; bitumen emulsion application (in designated plots).

This trial demonstrated that dilute bitumen emulsion did not inhibit germination of native seed. Seedling emergence was no different in plots stabilised with bitumen emulsion compared to control plots with no stabilisation (Figure 2). Emergence was substantially reduced in cereal rye plots (Figure 2) confirming this nurse crop's allelopathy on germinating seed (also seen in trials conducted at Eneabba in 2013; data not shown). There were many observations of 'zero' plant density and substantial variation in the observations. Consequently, the assessment method was changed in subsequent years from $4 \mathrm{~m}^{2}$ quadrats to VATs because they are more accurate, precise and time-efficient for estimating plant density (Engeman et al. 2005).

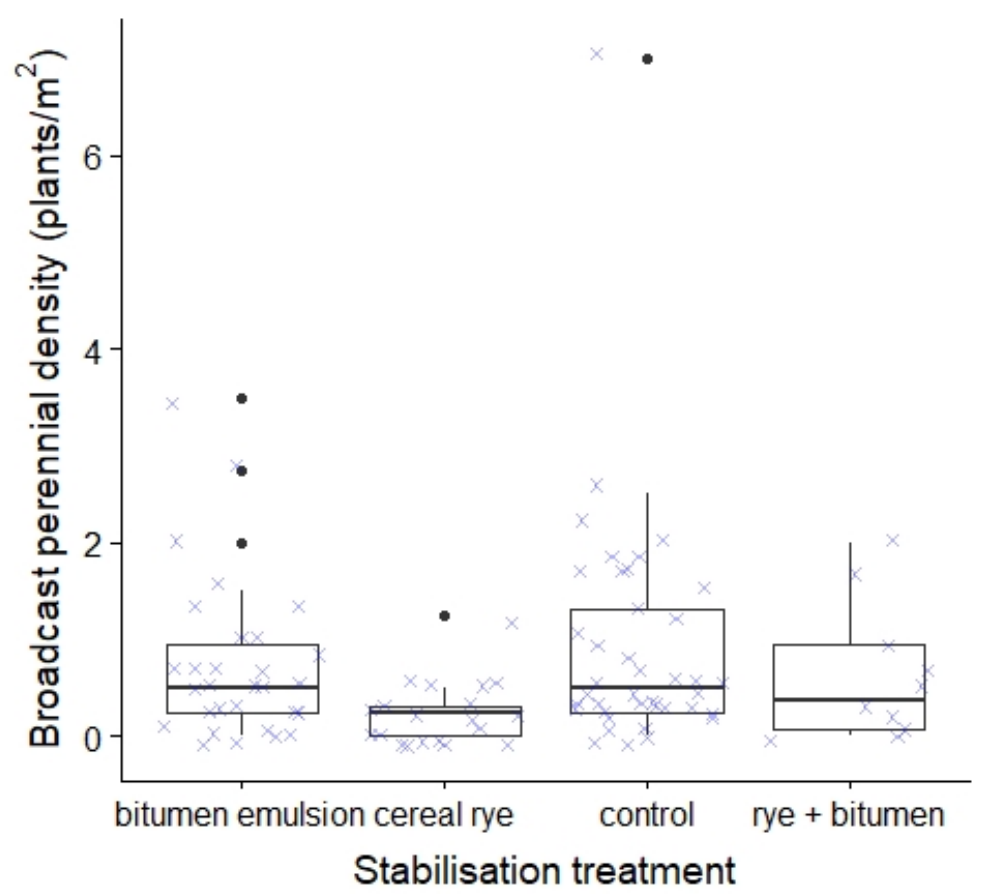

Figure 2 The effect of soil stabilisation treatment on emergence of broadcast perennial native seed

No residual hydrocarbons were detected within one week of applying the bitumen emulsion verifying its environmentally benign character if applied correctly: during fine weather with no rain for 24 hours, avoiding surface water features. Four composite samples (six locations for each composite) of the bitumen crust and 
top $5 \mathrm{~cm}$ of topsoil were collected and analysed (ChemCentre, Western Australia) for total recoverable hydrocarbons and polycyclic aromatic hydrocarbons, with nil detected.

Unfortunately, substantial sections of this trial were eroded by gullying from upslope water; two $100 \mathrm{~mm}$ rainfall events occurred within a single month in winter of 2015. This highlighted the need to improve water control using a different ripping technique in similar sloping areas of rehabilitation with upslope catchments. This improvement was made in 2016.

An estimate of the broadcast seed's viability was obtained from estimating emergence under ideal nursery conditions for germination (potting mix, irrigation, shelter). Compared to an estimated field emergence of $1.0 \mathrm{plant} / \mathrm{m}^{2}$ (Table 1 ), ideal nursery conditions produced 7-8 times more seedlings indicating substantial unrealised potential in the broadcast seed.

Table 1 Broadcast seed emergence of perennial natives in different years of rehabilitation

\begin{tabular}{lcccc}
\hline Rehabilitation year/treatment & $\begin{array}{c}\text { Mean broadcast } \\
\text { perennial seed } \\
\text { emergence (plants/m }\end{array}$ & $\begin{array}{c}\text { Lower } 95 \% \\
\text { confidence } \\
\text { interval }\end{array}$ & $\begin{array}{c}\text { Upper 95\% } \\
\text { confidence } \\
\text { interval }\end{array}$ & $\mathbf{n}$ \\
\hline 2015 rip (bitumen treatment only) & 1.0 & 0.54 & 2.1 & 10 \\
2016 rip/mound & 1.3 & 1.0 & 2.0 & 20 \\
2017 rip/mound/chain & 1.4 & 0.92 & 2.1 & 20 \\
2017 imprinting & 2.5 & 1.8 & 3.9 & 10 \\
2018 rip/seed burial/imprinting & 3.7 & 3.1 & 4.3 & 30 \\
\hline
\end{tabular}

\subsection{6 rehabilitation practice}

In an effort to improve water erosion resistance and water infiltration, rehabilitation practice in 2016 used a D10 dozer with a rip/mounding tine with a ploughing action that overturns soil to create more pronounced troughs (Figure 3 ) than produced by the winged tine used in 2015. An air-seeder and fertiliser spreader were also mounted on this D10 dozer, automating seed broadcast on the ripped ground. Dilute bitumen emulsion was applied at the same rate as in 2015 rehabilitation by a boom spray from a water tanker traversing the adjacent, unripped ground, thereby minimising re-compaction (Figure 3).

Rehabilitation performance, as measured by the emergence of broadcast perennial native seed, was similar to that seen in 2015 ripped and bitumen emulsion treated rehabilitation (Table 1). No water erosion occurred with the rip/mounding practice, which efficiently held all rainfall on the site for infiltration in the troughs created by the rip/mounding. Wind erosion was also solved with bitumen emulsion application.

Some critical observations were made of the pattern of seedling emergence across the soil surface. Areas of topsoil undisturbed by the rip/mounding and located between troughs - 'flat areas' - had prolific emergence (Figure 4). These 'flat areas' had topsoil at the soil surface and also acted as micro-catchments, unlike the troughs where the action of the rip/mounding tine buried the topsoil, exposing clayey subsoil, and the continuous nature of the troughs directing water flow downslope (rip lines can never be perfectly on the contour in practice). In addition, when monitoring with VATs, the location of all seedlings - in the trough or slope, or in the 'flat areas' - was noted. Broadcast perennials were on average 1.6 times more likely (95\% confidence interval $[0.98,2.6])$ to emerge on the 'flat areas' than on the trough/slope of the rip/mounded rehabilitation surface, and Myrtaceae species in particular 3.5 times [1.4, 7.5] more likely. Conversely, the topsoil-derived Acacia species and weeds were equally likely to emerge in either location (1.0 times [0.65, $2.3]$ and 0.89 times $[0.48,1.8]$, respectively). The preference for at least some broadcast seed to emerge on these topsoil-covered micro-catchments stimulated the search for a method of creating these artificial microcatchments, hence to trialling land imprinting. 

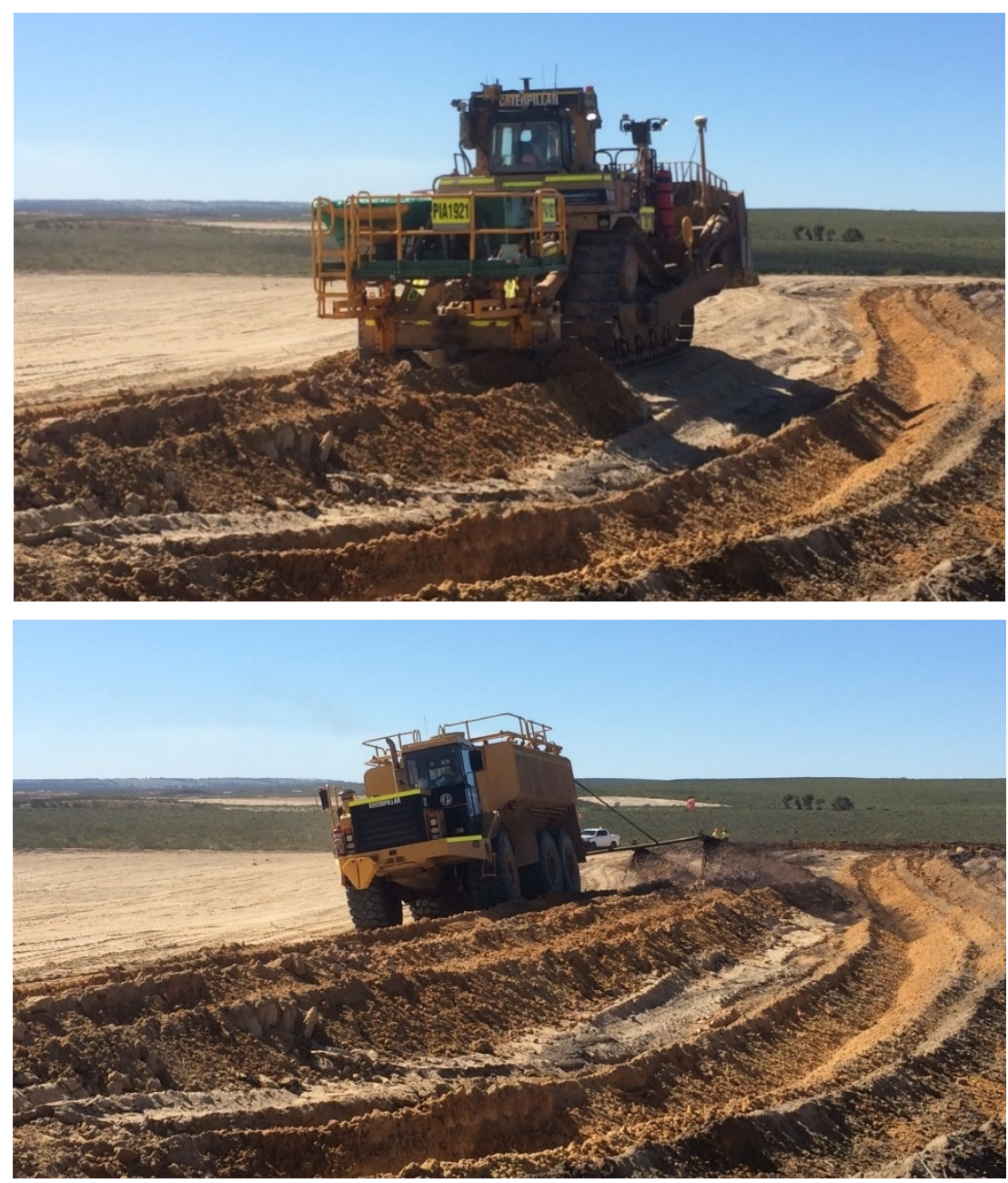

Figure 3 Rehabilitation practice in 2016 showing rip/mounding with seed and fertiliser broadcast (top) and application of dilute bitumen emulsion by water tanker from the unripped surface (bottom)

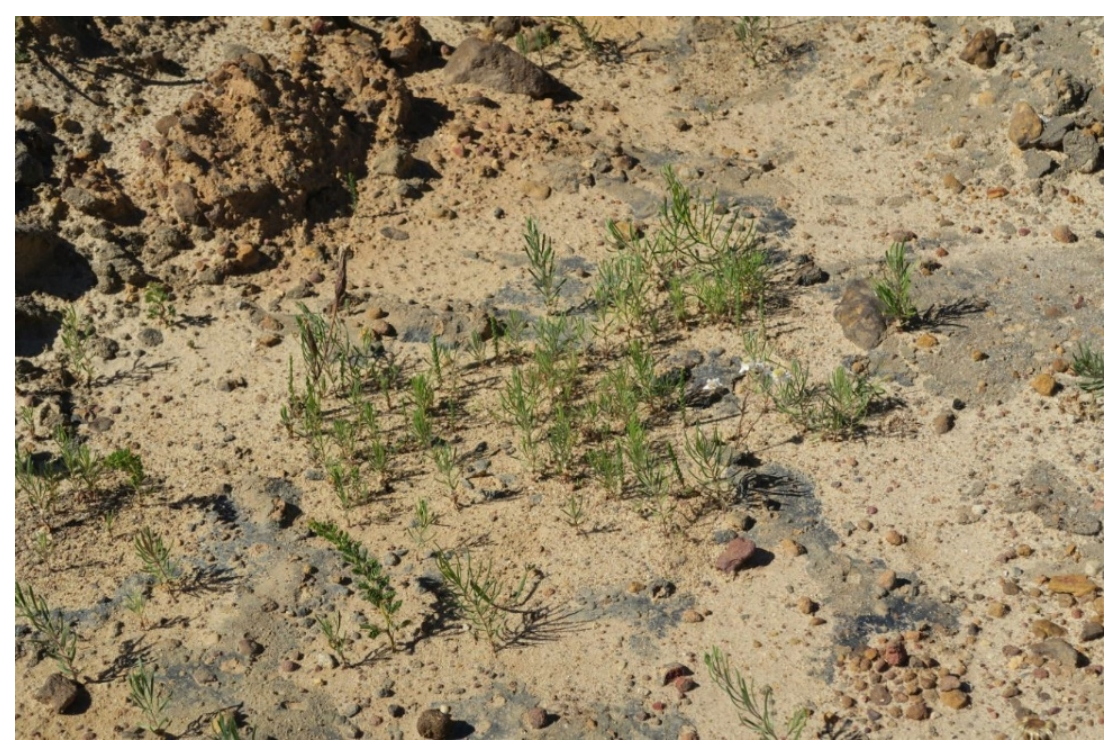

Figure 4 'Flat areas' on the 2016 rehabilitation surface where seedlings preferentially emerged 


\subsection{7 land imprinting trial}

In 2017, the ripping practice was modified to create more 'flat areas' for enhanced seedling emergence. The $\mathrm{rip} / \mathrm{mound} / \mathrm{chain}$ equipment used and the surface created, then stabilised, can be seen in Figure 5. The seeding, fertilising and bitumen emulsion application was identical to 2016 practice.

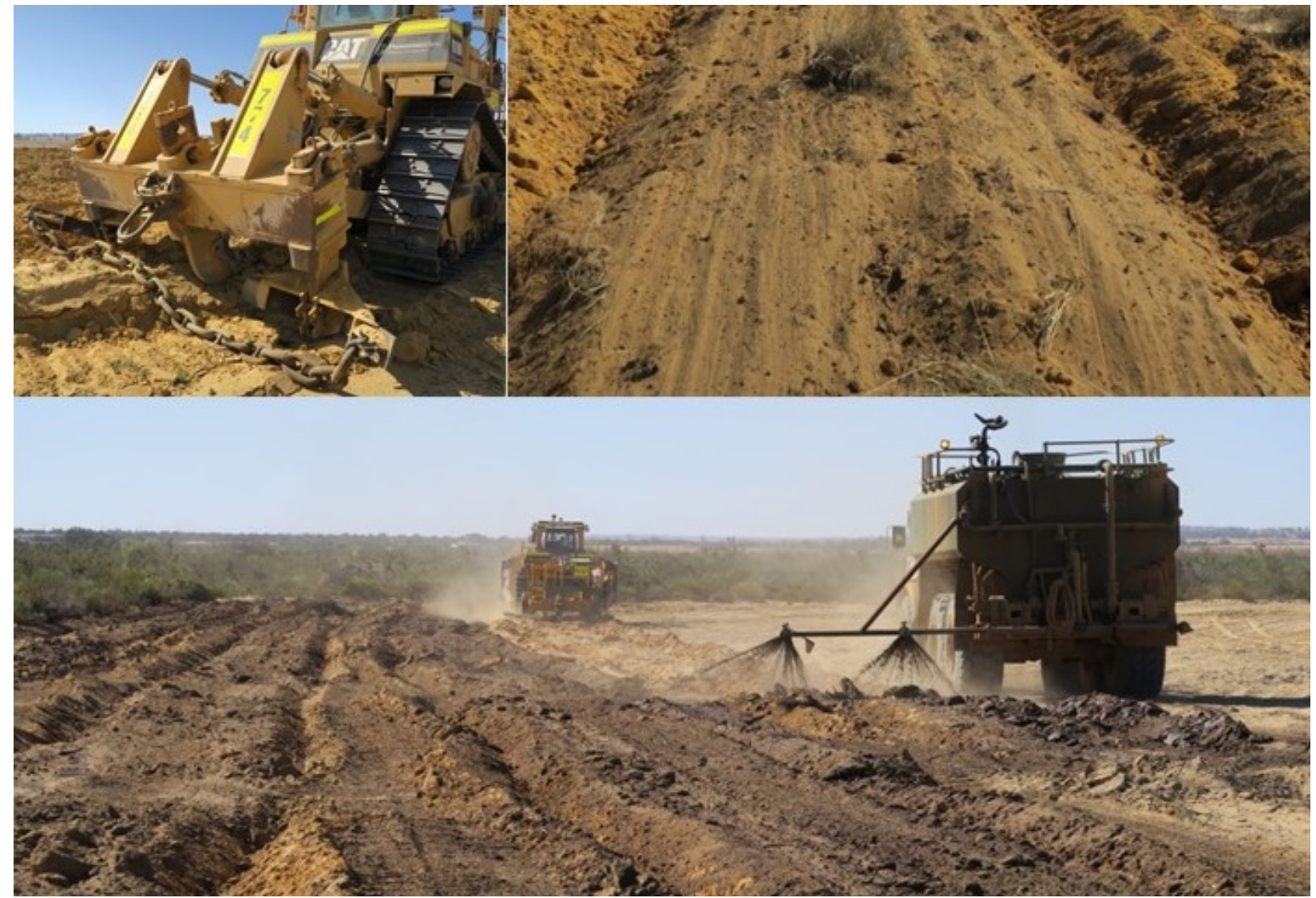

Figure 52017 rehabilitation rip/mound/chain equipment (top left) that created more 'flat areas' (top right), these were seeded and sprayed with dilute bitumen emulsion (bottom) similarly to 2016 rehabilitation

In 2017, land imprinting was trialled. Of the approximately 30 ha of rehabilitation completed in 2017, 2 ha across two locations was land imprinted with a pilot-scale imprint roller (Figure 6). Seeding and fertilising (performed prior to imprinting), and bitumen emulsion application (performed after imprinting) were identical to other areas rehabilitated in 2017 , hence general rehabilitation practice was a control comparison for the imprinting trial.

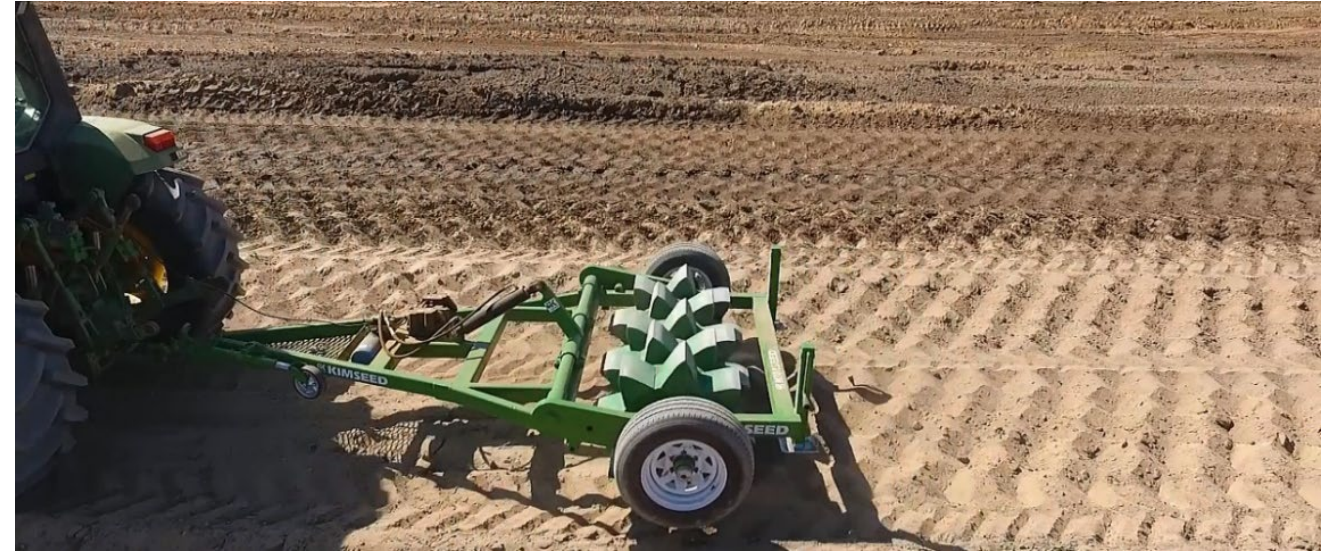

Figure 6 Land imprinting in the foreground with bitumen emulsion stabilised imprints in the background 
Land imprinting resulted in a two-fold increase in emergence of broadcast perennials (Table 1; Figure 7) and a three-fold increase in emergence of topsoil-derived Acacia species (Figure 7) compared to the $\mathrm{rip} / \mathrm{mound} / \mathrm{chain}$ areas of 2017 rehabilitation. Equally important in the imprinting trial was the absence of bare patches where no broadcast seed emerged: no imprinted VATs recorded less than one plant $/ \mathrm{m}^{2}$ of either broadcast or topsoil-derived seedlings compared to many in the rip/mound/chain areas (Figure 7). This is an indication of more consistent seedling emergence across the surface of imprinted areas, which is readily observed in photographs of the side-by-side comparison (Figure 8). The side-by-side comparison of imprinted and rip/mound/chain areas also shows that the seedlings grow more vigorously over time. This could be indicative of the greater infiltration of water expected on imprinted ground since little or no runoff occurs (Figure 9).
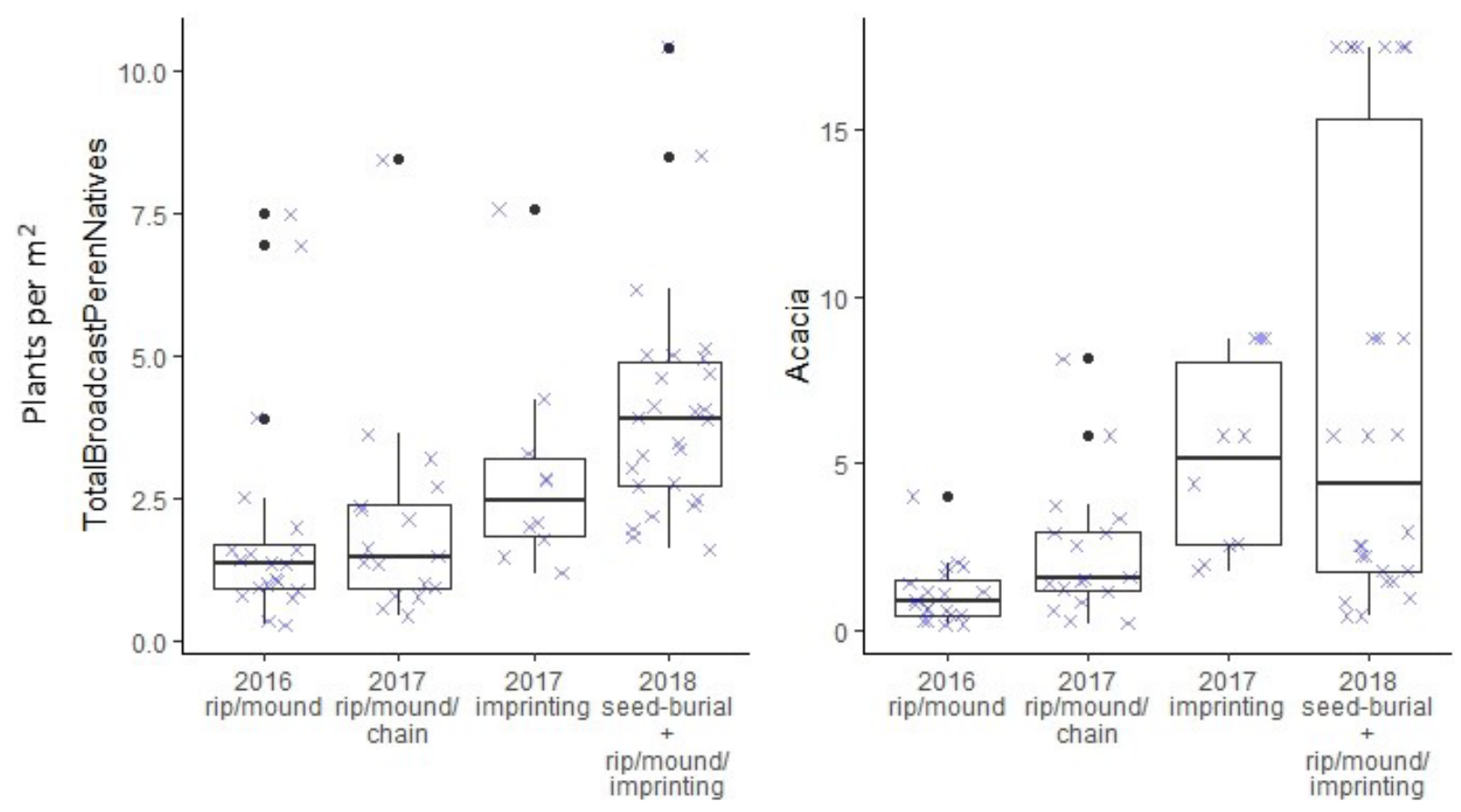

Year and rehabilitation practice

Figure 7 Emergence of broadcast perennials and topsoil-derived Acacia species in 2016, 2017, 2017 imprinting and 2018 rehabilitation areas

Similarly, to observations made in 2016, across the surface of the rip/mound/chain rehabilitation in 2017, the 'flat areas' were even more likely to favour emergence of broadcast perennial species, 4.9 times [3.3, 6.8], than troughs created by the ripping. It was speculated that the chain was burying seed on the 'flat areas' leading to greater likelihood of their germination and emergence. Other serendipitous observations were made of simple seed burial at 10-20 mm depth greatly increased seedling emergence. (These observations were made in unrelated native seed enhancement and native seed pathology trials in 2016 and 2017 rehabilitation.) All of these observations led to equipment modifications in 2018 rehabilitation practice aiming to increase seed burial. 


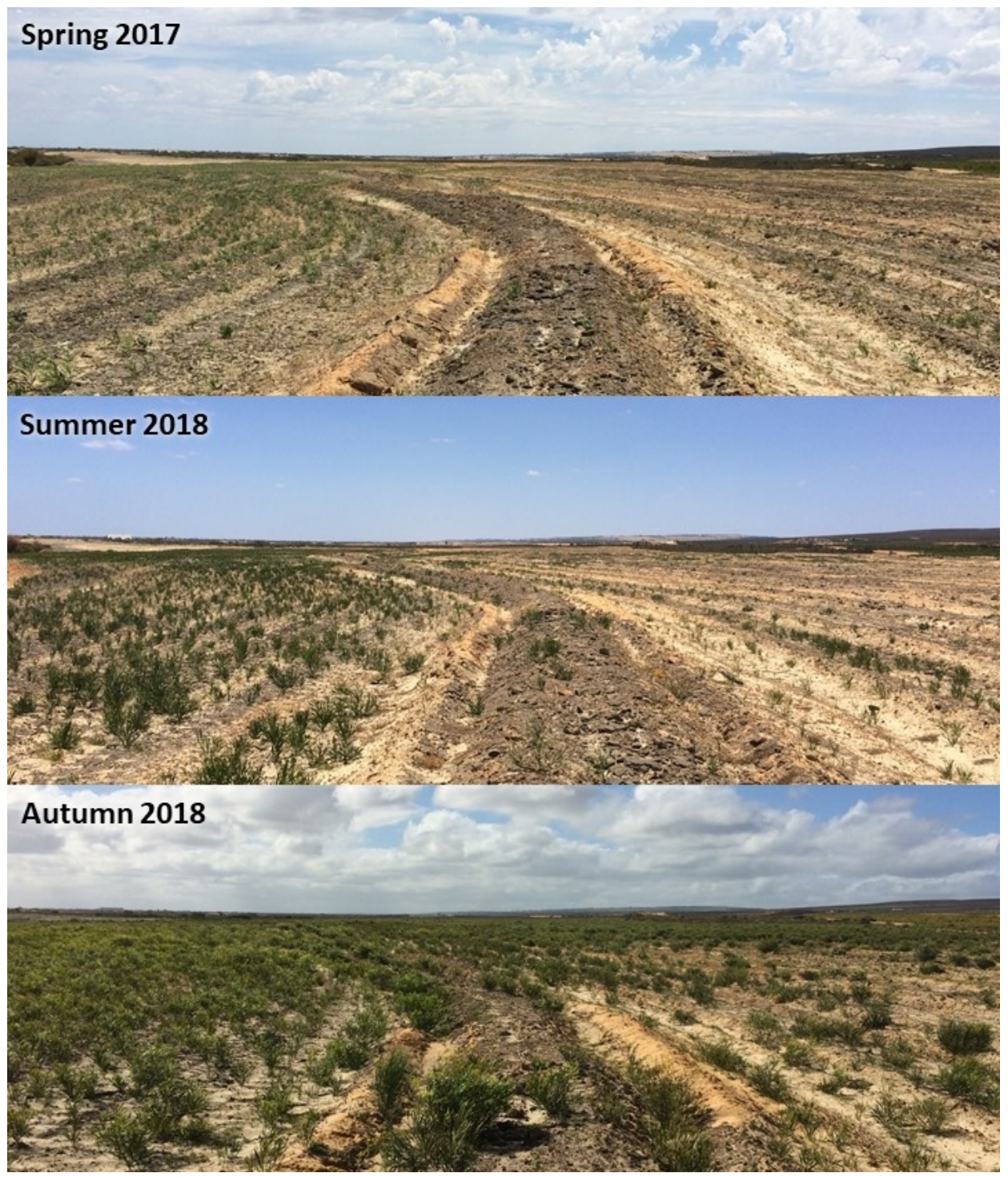

Figure 8 Comparison of land imprinted (left side of images) versus rip/mound/chain rehabilitation (right side of images) over time

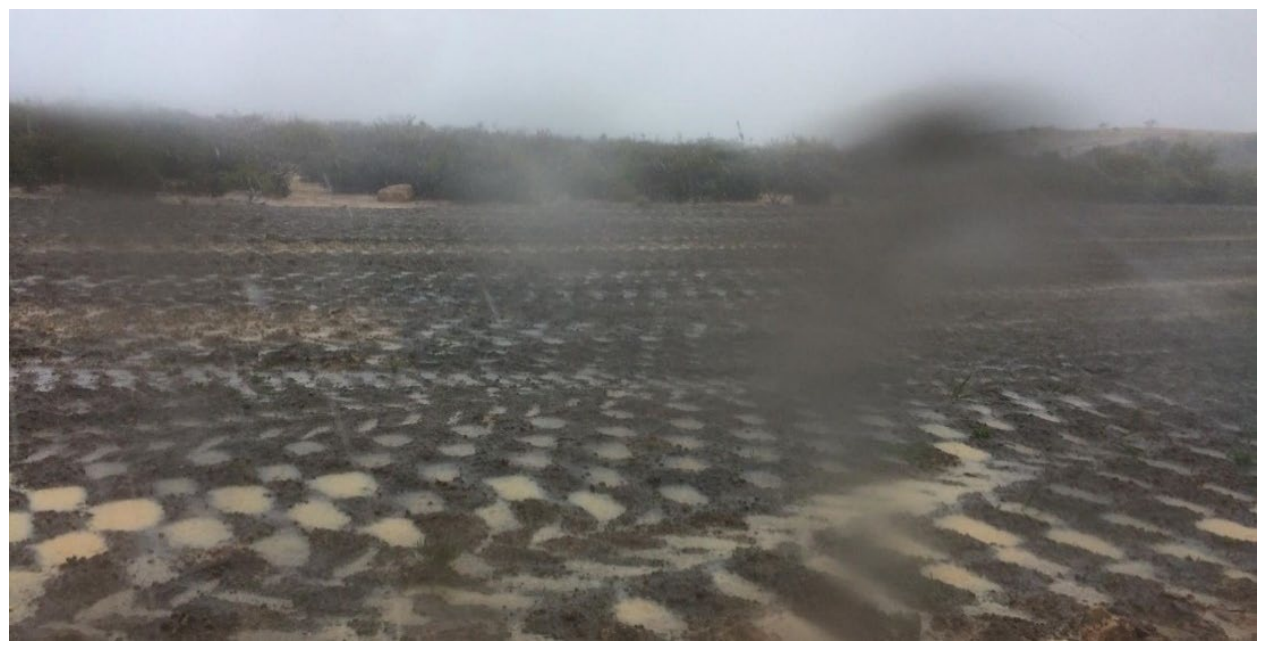

Figure 9 Land imprinting photographed during a $20 \mathrm{~mm} / \mathrm{h}$ rainfall event with no runoff observed 


\subsection{8 seed burial and imprinting}

Rehabilitation practice at Eneabba in 2018 sought to incorporate the imprinting process as well as seed burial. $\mathrm{Rip} / \mathrm{mound} /$ chaining, air-seeding and fertiliser spreading from a D10 dozer was identical to 2017 practice. To achieve seed burial, stump-jump harrows were added to the dozer to groove the sandy surface allowing seed to fall in those grooves (Figure 10). An additional pass with the tractor-drawn imprint roller closed those grooves, burying seed, while also imprinting the soil surface. The usual side-boom spray of bitumen emulsion completed the process, although in 2018 less emulsion was used (approximately 16,000 L/ha of 1 in 20 dilution of ASS-60). In hindsight, this rate of bitumen emulsion was too dilute to resist wind erosion adequately so future years' work will return to the original dilution.

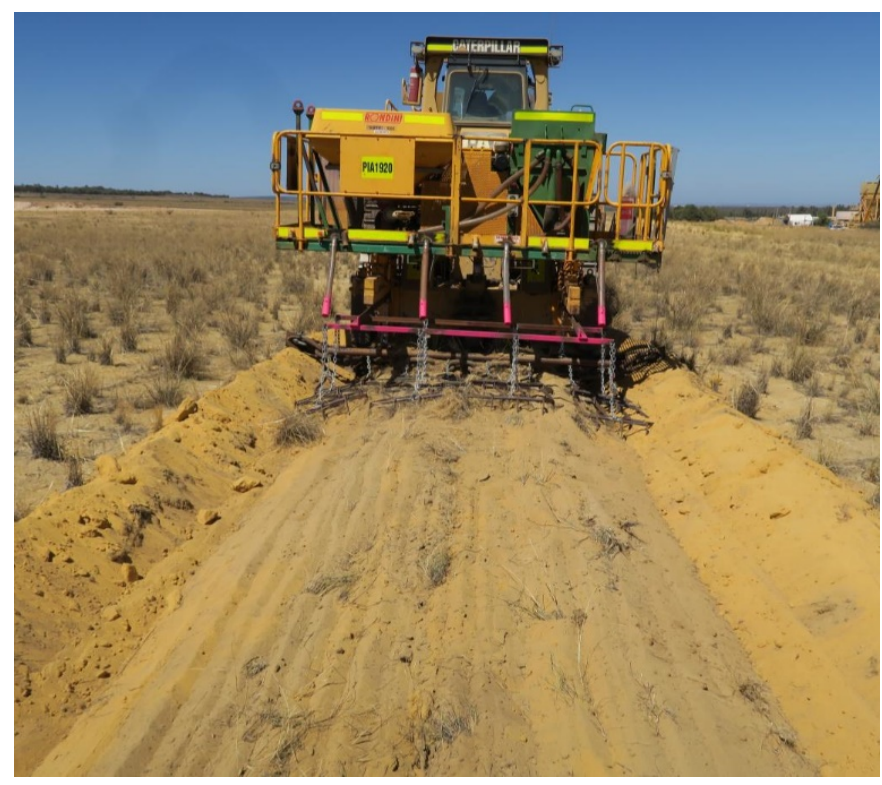

Figure 10 D10 dozer with rip/mound/chain pulling stump-jump harrows to create grooves for seed burial

Seedling emergence rates in 2018 of broadcast perennials and topsoil-derived Acacia species again increased compared to the previous year of both $2017 \mathrm{rip} /$ mound/chain rehabilitation and 2017 imprinting (Figure 7). However, the increase is unlikely to be statistically significant given the $95 \%$ confidence interval overlap (Table 1). Similar to 2016 and 2017 rehabilitation, broadcast perennials were 3.3 times [2.4, 4.3] more likely to emerge on 'flat areas' of the rehabilitation surface than in troughs. Topsoil-derived Acacia species and weeds did not show that preference $(1.2$ times $[0.85,2.2]$ and 1.3 times $[0.86,2.6]$, respectively).

\subsection{Critical analysis}

The comparisons made in the performance of rehabilitation practices among rehabilitation done in different years potentially suffers from three problems:

- The broadcast seed collected was different each year, possibly with different viability.

- Weather conditions differed between years and may have favoured more germination and emergence in particular years.

- Site conditions, particularly the topsoil used, differed between years.

Comparing the rehabilitation practice between years using broadcast perennial emergence as the comparator minimises these problems. The comparison is considered valid because:

- A large number of species are aggregated in the broadcast perennial emergence metric thereby reducing the overall effect of viability differences in particular species. 
- Weather conditions have greater effect on emergence of annual species, specifically excluded from the comparison, and in the period 2015-2018 there were sufficient winter rains each year for emergence of perennials.

- Topsoil-derived species (A. blakeyli and A. pulchella) were excluded from the comparison and the topsoil quality was poor for all rehabilitation areas.

That imprinting with bitumen emulsion promotes a substantial increase in, and consistency of broadcast seed emergence has been clearly demonstrated in 2017 trials, if not also confirmed through monitoring in 2018 rehabilitation.

The focus this study has given to early assessment, within 6-8 months, of rehabilitation seeding deserves comment. There are two major reasons for this early assessment of rehabilitation progress: pragmatic and biological. The pragmatic reason is to obtain feedback rapidly and in time to adjust the following year's rehabilitation practice. Monitoring of rehabilitation for regulatory reporting is not undertaken until 18 months after seeding, once the vegetation has passed two winters and its first summer. This is ideal for species identification, but the scale, intensity and type of monitoring undertaken for regulatory reporting does not provide accurate or precise estimates of seeding success: the conversion of broadcast seed into plants. The VAT monitoring used here does provide those estimates, and efficiently. The biological reason for early assessment is that seed germination and emergence is a key limiting step in plant recruitment (Lamichhane et al. 2018) and therefore a critical first hurdle to restore vegetation. Early assessment also removes the added year-to-year variability of the first summer's mortality of seedlings.

This work confirms other studies (Montalvo et al. 2002) that demonstrate the benefit of land imprinting. However, the novelty of this work is combining an artificial soil crust (dilute bitumen emulsion) with land imprinting in sandy textured soils in which imprinting would not otherwise be effective. Further confirmation of the improved emergence of broadcast seed using this combination of rehabilitation techniques in other environments or sites would be useful to confirm this method's general applicability.

\section{$4 \quad$ Future directions}

The improvements to rehabilitation practice that have been demonstrated through these trials and monitoring at Eneabba has stimulated lluka to redesign its rehabilitation process and equipment. It was clear that ripping with a D10 dozer using aggressive rip/mounding action, although highly effective for control of surface water flows and erosion, was not providing a suitable seed bed for broadcast seed. Also, given deep ripping has been thoroughly researched in agricultural contexts not too dissimilar to mineral sands rehabilitation (unlike many other mining operations), we are adopting agricultural methods for ripping where appropriate: tractor-drawn trailers with multiple, hydraulically controlled tines. The ripping process is now separated from seeding, imprinting and spraying.

To capture the demonstrable benefits of seed burial, imprinting and spraying of bitumen emulsion, lluka with the assistance of local engineering company has designed and built a rehabilitation trailer (Figure 11). This trailer can spread fertiliser, scarify the (often uneven and rocky) soil, air-seed the diverse size and shape seed mix, imprint and thereby bury the seed, and finally spray the surface with bitumen emulsion in one pass. Given the flexibility and functional control designed into this equipment, we intend to continue experimenting with the different aspects of the seeding process (seed burial, imprinting, bitumen emulsion) to understand each process's individual influence on seedling emergence in rehabilitation. 


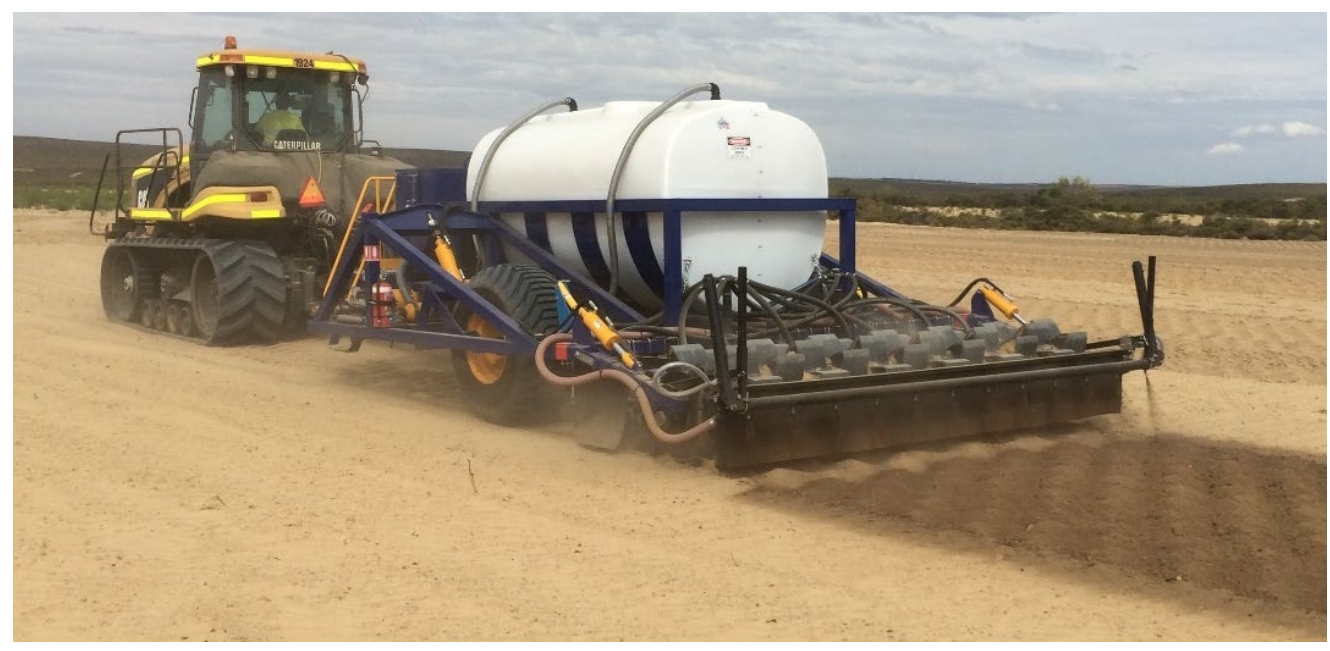

Figure 11 Purpose designed and built equipment to fertilise, scarify, seed, imprint and spray in one pass

\section{Acknowledgement}

The author wishes to thank Neil McMulkin, Rob Brown and Geoff Dyer, the lluka design team; Bob Smith, Roger Wilson and the rehabilitation team at Iluka Eneabba; Piacentini \& Son Mining and Earthmoving; Greg Davies and the team at Paragon Industrial/Primary Sales Australia; Kimseed; and Iluka Resources management for supporting this work.

\section{References}

Bainbridge, DA 1996, 'Land imprinting to revegetate drylands and deserts', A section of the 1996 technical report: Revegetation in Arid Environments, prepared for CalTrans Biology, San Diego, Soil Ecology and Restoration Group, SDSU, San Diego.

Barnes, JP \& Putnam, AR 1986, 'Evidence for allelopathy by residues and aqueous extracts of rye (Secale cereale)', Weed Science, vol. 34, no. 3, pp. 384-390.

Bell, DT, Carter, DJ \& Hetherington, RE 1986, 'Experimental assessment of wind erosion after soil stabilisation treatments at Eneabba, Western Australia', Environmental Geochemistry and Health, vol. 8, pp. 99-104.

Bellairs, SM \& Bell, DT 1993, 'Seed stores for restoration of species-rich shrubland vegetation following mining in Western Australia', Restoration Ecology, vol. 1, pp. 231-240.

Dixon, RM 1995, 'Water infiltration control at the soil surface: Theory and practice', Journal of Soil and Water Conservation, vol. 50, no. 5, pp. 450-453.

Dixon, RM \& Peterson, AE 1971, 'Water infiltration: a channel system concept', Soil Science Society of America Proceedings, vol. 35, pp. 968-973.

Engeman, RM, Nielson, RM \& Sugihara, RT 2005, 'Evaluation of optimised variable area transect sampling using totally enumerated field datasets', Environmetrics, vol. 116, pp. 767-772.

Granada-Isaza, CA, Ventura-Ramos Jr., E \& Oropeza-Mota, JL 2012, 'Reinforcement of soil imprinting with gypsum and polyacrylamide to control water erosion and runoff', Terra Latinoamericana, vol. 30, pp. 69-79.

Lamichhane, JR, Debaeke, P, Steinberg, C, You, MP, Barbetti, MJ \& Aubertot, J-N 2018, 'Abiotic and biotic factors affecting crop seed germination and seedling emergence: a conceptual framework', Plant and Soil, vol. 432, pp. 1-28.

Montalvo, AM, McMillan, PA \& Allen, EB 2002, 'The relative importance of seeding method, soil ripping, and soil variables on seeding success', Restoration Ecology, vol. 10, pp. 52-67.

R Core Team 2013, R: A language and environment for statistical computing, version 3.5.3, computer software, R Foundation for Statistical Computing, Vienna.

Sánchez-Moreiras, AM, Weiss, OA \& Reigosa-Roger, MJ 2003, 'Allelopathic evidence in the Poaceae', The Botanical Review, vol. 69, no. 3, pp. 300-319.

Tongway, DJ \& Ludwig, JA 1997, 'The conservation of water and nutrients within landscapes', in JA Ludwig, DJ Tongway, DO Freudenberger, JC Noble \& KC Hodgkinson (eds), Landscape Ecology, Function and Management: Principles from Australia's Rangelands, CSIRO Publishing, Melbourne.

Tsakalos, JL, Renton, M, Dobrowolski, MP, Feoli, E, Macintyre, PD, Veneklaas, EJ \& Mucina, L 2018 'Community patterns and environmental drivers in hyper-diverse kwongan scrub vegetation of Western Australia', Applied Vegetation Science, vol. 21, pp. 694-722.

van der Westhuizen, C, Rintoul, L \& Baumgartl, T 2011, 'Mined sand dune rehabilitation success on North Stradbroke Island - a study of the origin and effects of hydrophobicity', Proceedings of the Royal Society of Queensland, vol. 117, pp. 365-376.

Wilcox, R 2012, Introduction to Robust Estimation \& Hypothesis Testing, 3rd edn, Elsevier, Amsterdam. 